\title{
Management of Agricultural Crops
}

\section{Safdar Bashir*}

Institute of Soil and Environmental Science, University of Agriculture Faisalabad, Pakistan

*Corresponding Author: Safdar Bashir, Institute of Soil and Environmental Science, University of Agriculture Faisalabad, Pakistan.

Received: April 22, 2019; Published: June 01, 2019

DOI: 10.31080/ASAG.2019.03.0506

It is predicted that our planet will be populated with 9 billion people in 2050. This will result in serious issues with food, water and energy supply, particularly in less-developed countries. Considering the human demand; pressure on natural resources has already reached its critical limits. International organizations such as the World Bank and UN Food and Agriculture Organization (FAO) are asking scientific research in order to identify innovative solutions to increase the current growth many to many folds to meet the future food demands.

Agriculture growth and increase in agriculture productivity are the main contributors in sustaining economic growth and development of the countries. Currently, agriculture also remained as important part of many developing countries in sustaining economic growth and reduction in poverty. Additionally, agriculture and it associated enterprises can have major impact on the environment. Well managed agriculture can boost income, conserve soil and water resources, preserve tree and biodiversity and contribute to mitigate climate change issues. Badly managed agriculture practices can lead to food insecurity, environmental degradation and pollution, natural resource depletion, contaminated food and poor nutrition and health.

In current situation, with respect to increasing profitability, even the intensively managed cropping systems are becoming unsustainable. It is the demand of the time now, that the next phase of the Green Revolution must be triggered with a paradigm shift from the less efficient conventional farming towards an efficient farming system; So that agriculture productivity and sustainability can be optimized.

Future food production systems need to adopt, not only to increase yields to meet the increasing population demands using less land, water and nutrients, but also to reduce their impacts on climate and susceptibility to warmer temperatures and altered rainfall patterns due to climate change. Linking challenges of climate change and competition for land, water and energy require attention in the areas of bridging the gap between actual and potential productivity levels in the agriculture of developing countries, investing in agricultural innovation, and improving national and international research co-operation.

Agricultural management needs innovation in all sectors of agricultural production system ranging from land preparation till storage of the produce. The decisions made by farmers before he commences crop production have great impact on the overall profitability. Efficient management in all sectors including, water management in relation to crop moisture requirements, tillage and land preparation, liming or acidity control, fertilizer use, and crop protection have great importance in sustaining future food demands. By developing and implementing sustainable crop management practices, one can improve not only the livelihood of the rural population but also food security can be ensured.

The current issue will cover the aspects mentioned above as well as new developments in agricultural crops management. I hope this issue will be of great concern for the relevant stakeholder including scientist, farmers and policy makers to explore novel technique in agricultural management.

\section{Volume 3 Issue 7 July 2019 (C) All rights are reserved by Safdar Bashir.}

